\title{
New collaborations in old institutional spaces: Setting a new research agenda to transform Indigenous-Settler relations
}

\author{
Sarah Maddison and Sana Nakata
}

\section{Introduction}

In 1957, the very first Indigenous Australian enrolled in a University degree. Two years later, Margaret Williams-Weir, graduated from The University of Melbourne with a diploma in physical education. It would be another seven years before Charlie Perkins would graduate from The University of Sydney, and eight years before the Australian public would vote to count them among the peoples of the nation in the 1967 referendum. In the decades that followed, the numbers of Indigenous Australian university students have increased markedly. Bill Jonas became the first Aboriginal Australian to receive a PhD in 1980, and Martin Nakata, the first Torres Strait Islander to do so, would follow in 1997. Margaret Williams-Weir would eventually return to study and graduate with her doctorate in the 2000s before passing away in 2015. In total, only 55 Aboriginal and Torres Strait Islander students were awarded PhDs in Australia between 1990 and 2000, but 219 Indigenous students earned doctorates in the 11 years to 2011 (see Bock 2014 for more).

These numbers suggest that landscape of higher education and research in Australia has been radically transformed. The inclusion of Aboriginal and Torres Strait Islander students in classrooms, the thousands of university graduates that now populate an emerging Indigenous professional class, and the hundreds of $\mathrm{PhD}$ graduates and candidates currently seeking to make an impact on the academy indicate that a corner has been turned with regard to supporting, recognising, and rewarding Indigenous intellect and success. More than this, Indigenous knowledges now inform teaching and research in many institutions of higher education. Although an incomplete project, the fracturing of the hegemony of Western/settler knowledge is underway.

The same cannot be said for the domain of politics and public policy - both in practice and in scholarship. In practice, during this same period, the landscape of Australian Indigenous policy 
has, at one level, remained remarkably unchanged. Aboriginal and Torres Strait Islander peoples remain a population of comparison, known and made sense of in relation to the lives and experiences of the non-Indigenous Australian 'norm'. As a point of comparison, Aboriginal and Torres Strait Islander peoples are framed in terms of deficit, continually presented as a problem for Australia's policy makers to solve. Poor statistical indicators are conceptualised only as an issue of disadvantage, rather than as a problem stemming from the political relationship between Indigenous peoples and the state, which in turn continues to shape the social determinants of Indigenous health and wellbeing (see Carson et al 2007). This framing relies on what Palawa sociology scholar Maggie Walter (2018: 258) describes as '5D Data': data that focuses on difference, disparity, disadvantage, dysfunction and deprivation rather than on the lived experiences of Aboriginal and Torres Strait Islander peoples, and it directs policy attention only towards Indigenous lives and behavior and away from the structural reform they seek (Davis 2018).

When Aboriginal and Torres Strait Islander peoples themselves are understood as the problem, then changing the policy settings to 'fix' them seems like the solution. This deficit paradigm has received increasing critical attention, and with it, efforts to reframe Indigenous research through the lens of success and strength have emerged. However, this deficit/success binary remains wedded to a persistent political discourse that insists on framing Indigenous people in Australia as objects to be studied, and problems to be solved, whether through the recognition of success and strength on their own terms, or through the elusive achievement of 'closing the gap'. Both approaches act upon Indigenous people as subjects of domestic policy, and both demonstrate the settler state's assertion of sovereign authority over Indigenous peoples. The settler state conflates Indigenous affairs with concerns about crime, delinquency, and neglect (Wolfe 2016: 37-80), while political debate focuses on Indigenous wellbeing (or lack thereof), allowing governments of all persuasions to represent their policy initiatives as forms of goodwill and benevolence (Strakosch 2015: 52).

Alongside this stasis, however, the Indigenous affairs domain has also been marked by constant change, and endless churn and reinvention, as settler efforts to 'solve' the 'Indigenous problem' continue to fail. During the last 50 years there have been 21 different ministers in the Indigenous portfolio, and ten different organisational structures, nine of which have been created/dismantled within the past 30 years. These endless changes have worsened already complex problems in the Indigenous policy domain, embedding uncertainty and scepticism, 
and fracturing fragile relationships that have often taken years to establish (Patterson 2017: 1516). These administrative changes have been accompanied by extreme ideological swings: between self-determination and intervention, autonomy and paternalism-swings often articulated in competing intellectual visions such as in debates about the place of the 'real' or the 'hybrid' economies in remote Indigenous communities (see Curchin 2015). For Aboriginal and Torres Strait Islander people, the experience of constant policy change has been frustrating, destabilising and disempowering, underscoring settler disregard for Indigenous sovereignty and autonomy. Yorta Yorta and Dja Dja Wurrung woman Muriel Bamblett has described this experience as like being 'caught in a big washing machine':

You've got change all the time; every time we just get used to something you move to another cycle and the cycle keeps changing and we keep moving and we haven't got used to the last cycle before we're moving on to the next cycle (quoted in Maddison 2009: 3).

The endless debate and constant turmoil in Indigenous affairs lends weight to Wolfe's (2016: 37-8) observation that settler colonial societies direct a disproportionate amount of energy and effort towards administering the lives of Indigenous peoples, despite the fact that (as in Australia) they tend to be statistically very small groups in the society.

Alongside these discursive challenges and the administrative and ideological churn, Aboriginal and Torres Strait Islander people continue to navigate the social and political order of the Australian settler state in ways that seek to increase their personal freedoms and political autonomy. For some groups this means seeking a firmer place within the social, political and economic life of Australia, and for others it means navigating away, towards a more distant relationship based in the resurgence of Indigenous nationhood. This paper argues that this navigation is composed of multifaceted and multidirectional relations between Indigenous Australians, settler Australians, and the settler state, and that it is toward these relations that the academy must now turn. The transformation of Australian social, political and economic life such that the full ambitions of Aboriginal and Torres Strait Islander people as individuals and nations might be realised requires attention to new and different kinds of politics, and necessitates research that considers the dynamics and structures of Indigenous-settler relations as a matter of priority. Our focus on relationality here is not because Indigenous Australians 
exist only in relation to the state, but because the state only exists in relation to its dispossession of Aboriginal and Torres Strait Islanders. As a discipline, political science must move beyond the study of settler institutions as though they are either neutral or benign, and begin instead to engage more comprehensively and rigorously with the colonial implications of these institutions in the lives of Aboriginal and Torres Strait Islander peoples, and in the relations between Indigenous peoples and the state that they delineate and sustain.

As a discipline, political science must move beyond the study of settler institutions and begin to engage more comprehensively and rigorously with the implications of these institutions in the lives of Aboriginal and Torres Strait Islander peoples, and in the relations between Indigenous peoples and the state that they delineate and sustain.

\section{The Impasse in Relations - reframing the problem}

It is no exaggeration to claim that relations between Aboriginal and Torres Strait Islander peoples and the Australian settler state are at an impasse. In the wake of the Turnbull Government's rejection of the Statement from the Heart in 2017 there is no shared view on how the relationship between Aboriginal and Torres Strait Islander peoples and the settler state and its peoples might now be navigated.

The Statement from the Heart in 2017 drew attention to the need for structural reform in the relationship between Aboriginal and Torres Strait Islander peoples and the state, and explicitly rejected the framing of Indigenous people as the problem to be worked on:

Proportionally, we are the most incarcerated people on the planet. We are not an innately criminal people. Our children are aliened from their families at unprecedented rates. This cannot be because we have no love for them. And our youth languish in detention in obscene numbers. They should be our hope for the future.

These dimensions of our crisis tell plainly the structural nature of our problem. This is the torment of our powerlessness (Referendum Council 2017, our emphasis).

The Statement expresses the challenges that shape the lives of Indigenous Australians incarceration, family separation - without making the lives of Indigenous Australians problems 
to be solved. Instead, the Statement makes a problem of the structure that governs the relationship between Aboriginal and Torres Strait Islander peoples and the Australian settler state. Addressing these structural problems is at the centre of the claims in the Statement:

\begin{abstract}
We seek constitutional reforms to empower our people and take a rightful place in our own country. When we have power over our destiny our children will flourish. They will walk in two worlds and their culture will be a gift to their country (Referendum Council 2017, original emphasis).
\end{abstract}

In these extracts from the Statement it is evident that Aboriginal and Torres Strait Islanders are able to identify the persistent and urgent challenges that shape their communities, and articulate the fact that these challenges lie in the relations between Indigenous peoples and the settler state rather than within Indigenous people and their communities. The Statement is an effort to rearticulate the 'problem' of Australian Indigenous policy landscape, and in doing so the 'problem' can be seen as explicitly political in nature. The 'torment of our powerlessness' is not a 'torment' of deficiency, or innate dysfunction or criminality, but a torment of political deafness.

The torment of Indigenous powerlessness is a powerful political problem that goes to the heart of who Australia imagines itself to be, emanating from the nation's insistence that Aboriginal and Torres Strait Islander people lie beyond (or prior) to it. The torment in the Statement from the Heart operates as a verb, not a noun: it is torment that is being done to Aboriginal and Torres Strait Islander peoples by the settler state. And in understanding this torment as a verb, we are also able to witness this torment as relational: as something that is produced between peoples, as something structural that persists all the while the enduring energy of thousands of individuals seek to change it for the better.

At some level, this relational torment has been understood. There has been intermittent political attention on the relationship between Aboriginal and Torres Strait Islander peoples and the settler state. For example, in the 1967 referendum, the decade long formal reconciliation process, and the 2008 apology to the Stolen Generations. Problematically, however, the dominant political response has predominantly been framed by the idea that the work to be done to attend to the relationship is the work of 'reconciliation.' The Australian version of reconciliation has, however, been rightly criticised for its focus on educating non-Indigenous 
people, at the expense of addressing historical injustice or the negotiation of contemporary treaties. Megan Davis (2016) suggests that reconciliation in Australia has dissolved into a form of 'philanthrocapitalism' (embodied in the Reconciliation Action Plan program) rooted in the assumed benevolence of settler institutions and corporations rather than the challenges of structural reform. Davis considers this part of the exceptionalism of Australia's reconciliation process, which eschewed the 'twin pillars of truth and justice' that have been the bedrock of reconciliation processes elsewhere in the world. Aboriginal and Torres Strait Islander peoples have been denied the opportunity to pursue their claims regarding colonial injustice, and instead exhorted to focus only on future relations with settlers and the settler state.

So while the formal reconciliation process in Australia did introduce a new 'moral language' with which to speak about issues of colonial injustice, it did not resolve any of the questions that were raised by these issues (Pratt 2005: 157). There were no reparations, no significant improvements in socio-economic inequity between Indigenous and non-Indigenous people, and no treaty or 'document of reconciliation' that addressed the political grievances of Aboriginal and Torres Strait Islander peoples (Gunstone 2009: 147). Reconciliation in Australia was framed by the language of unity and nation-building, which provided Aboriginal and Torres Strait Islander peoples with 'a right to be incorporated into the Australian nation but not a right to refuse' (Short 2005: 274). It was hoped that through the formal reconciliation process the relationship might improve (on terms acceptable to the settler order), but it was never intended that it would be structurally reformed. It was never intended that Aboriginal and Torres Strait Islander peoples be anything other than slightly more equal constituents in the settler order. This is fundamentally at odds with Indigenous aspirations and remains the fundamental impasse in Indigenous-settler relations, and does little to disrupt the problematisation of Aboriginal and Torres Strait Islander peoples that prescribes the dominant policy responses.

\section{Contemporary Indigenous Policy Domain}

It is constituent of the torment perpetuated on Aboriginal and Torres Strait Islander peoples by the settler state that Australian government policy in Indigenous affairs continues on a perverse and paternalistic pathway despite manifold evidence of failure. As the statistics on government efforts to 'close the gap' stubbornly refuse to progress, settler faith in government efforts to 'improve' the lives of Aboriginal and Torres Strait Islander peoples continues unabated. 
Discussing the Productivity Commission's 2016 'Overcoming Indigenous Disadvantage' report, Elise Klein (2016: 2) notes that not only does the focus of analysis remain centred on Indigenous 'deficit' and on 'gaps' in socioeconomic outcomes, it also fails to 'look up' and consider either the impact of government ideology or 'the enduring will of settler society to continue to colonise.' Stan Grant echoes the frustration of many Indigenous people when he argues that while to 'outside eyes', this lack of change is understood as 'a failure of the people themselves', Indigenous people 'know that this is the legacy of history and generations of poor government policies':

Money is spent, houses are built, new programs are devised, and the malaise deepens. With each new era of policy-protection, integration, assimilation, or self-determination - the problem remains the same; communities themselves are rendered powerless with limited input into how they run their lives (Grant 2016: $185)$.

Yet despite this evidence of ongoing failure, the legitimacy of settler state jurisdiction over Indigenous people is rarely questioned (by non-Indigenous people). The familiarity of state bureaucracy allows colonial authority over Indigenous lives to be naturalised and invisibilised on the assumption that Indigenous peoples have already been incorporated within the settler regime remains unquestioned (Strakosch 2015: 9, 51). Indigenous disadvantage is now routinely used to justify paternalistic interventions that further assimilate Aboriginal and Torres Strait Islander people into the settler state (Howard-Wagner 2017: 3)

The failed Closing the Gap strategy is emblematic of this problem. The 'Closing the Gap' policy framework is a set of agreements made by the Council of Australian Governments that address seven specific targets that measure health (life expectancy, child mortality), education (early childhood education, school attendance, literacy and numeracy, Year 12 attainment), and participation in paid employment. The framework emerged from the 'Close the Gap' campaign spearheaded by the former Aboriginal and Torres Strait Islander Social Justice Commissioner Tom Calma in 2005, which called on the Government to take action that would make substantial progress towards equalising health, education, and life expectancy outcomes for Indigenous people within 25 years. Beginning in 2008, the Closing the Gap approach to tracking socioeconomic outcome has become a central plank of Indigenous affairs policy in Australia, 
and receives considerable public attention when the prime minister presents the annual ' $\mathrm{Closing}$ the Gap' report to parliament, as he or she has done since 2009.

Progress over the decade of the Closing the Gap framework has been minimal. The 2017 Closing the Gap Report showed some improvement in reading and numeracy for Indigenous children, and reducing infant mortality and smoking rates, but indicated that only one of these targets - to halve the gap in Year 12 attainment by 2020 - was 'on track' to be met. The 2018 report again showed some improvement, with three of the seven targets now on track, but with four targets-including the key one to close the 10-year gap in life expectancy between Indigenous and non-Indigenous Australians by 2031 - still lagging. The UN Special Rapporteur on the Rights of Indigenous Peoples Victoria Tauli-Corpuz has described Australia's lack of progress on these targets as 'woefully inadequate', and particularly unacceptable given that two decades of economic growth in Australia had not improved the level of social disadvantage experienced by many Aboriginal and Torres Strait Islander people (quoted in Brennan 2017b). These poor statistical indicators continue to confound and contradict the settler state's understanding of itself as fundamentally benign and even beneficial to Aboriginal and Torres Strait Islander people. The evidence that this is not so is by now incontrovertible. Despite constant churn in policy, a 'proliferation' of services, and government commitment to throwing 'considerable administrative machinery and public finance at the problem' (Moran 2016: 2-3) the statistical indicators stubbornly refuse to budge. Fundamentally, the Closing the Gap framework suggests that 'gap-closing' is a 'technical policy matter' rather than an issue of deep political significance (Markham and Biddle 2017: 2). The impasse continues.

Sustained failure in reaching the Closing the Gap targets has prompted a 'refresh' of the approach, being advanced by the Commonwealth Department of Prime Minister and Cabinet (DPMC 2017a: 3), which has acknowledged that governments in Australia 'need to work differently with Aboriginal and Torres Strait Islander Australians.' A part of the 'refresh' agenda is a renewed commitment from Australian governments to 'work in genuine partnership with Indigenous leaders, organisations and communities, to identify the priorities that will inform how governments can better design and deliver programs and services, to close the gap.' These are certainly positive commitments, but they are a very long way from what Davis describes as the 'sophisticated roadmap to closing the gap' outlined in the Statement from the Heart. Davis maintains that Indigenous people 'aren't looking for refresh as a priority ... The 
priority is structural reform' (quoted in Davidson 2018). Indeed, as Lyndon Murphy and his colleagues (2017) have argued,

The source of the problem lies in the encounter between two previously discrete peoples, and the dispossession and overrunning of one by the other. Statistics about disadvantage cannot capture that. Instead, they give the mistaken impression that disadvantage can be solved by policy-making on the terms of those who did the over-running. Policy on these terms has been unsatisfactory.

In continuing to render Indigenous Australians as a problem to be solved, or a gap to be closed, the Australian settler state continues to be accepted as the solution to black problems rather than the originating source of such problematisations. As a result, political controversies - such as the treatment of young people incarcerated at the Don Dale youth detention centre in the Northern Territory or the Sunrise 'debate' on Indigenous adoption - take on routine formulations.

In 2016, the ABCs Four Corners program broke a news story concerning regular, violent assaults upon a number of teenagers at the Northern Territory Don Dale Youth Detention Centre in Darwin, including stripping children naked, hooding and restraining them, and using teargas to quell their resistance. Graphic video footage evidencing the brutalisation of these young people, and the public outrage in response, resulted in Prime Minister Malcolm Turnbull announcing a Royal Commission into the Protection and Detention of Young People in the Northern Territory the morning after the program aired. The Four Corners report in fact followed numerous reviews and reports that had previously been undertaken into the detention system in the Northern Territory, which included the identification of 21 significant incidents at Don Dale, including one report of detainee assault on staff and five reports of staff assaults on detainees. The Northern Territory children's commissioner Howard Bath produced a 2012 report into the sustained maltreatment of Dylan Voller (one of the young people featured in the Four Corners report) in particular. Details of that maltreatment remained secret for two years, and received no substantive attention until the Four Corners program another two years later. Dylan Voller aside, on any given night, the Northern Territory detains children aged between 10 and 17 at three times the rate than the next highest rate in Western Australia, and at 11 times the rate of Victoria and Tasmania. In mid 2018, every single child detained in the Northern Territory was an Indigenous Australian child. 
At the time of the Four Corners report, the then Chief Minister of the Northern Territory, Adam Giles, seemed unable to decide whether Dylan Voller and kids like him were being locked up for their own safety or the safety of others:

There are kids who are trying to deliberately cause cranial issues by bashing their head against the wall... Prison officers need the ability to be able to de-escalate issues when children are not in ... a calm environment within themselves and at all times those kids' wellbeing is being put at the best possible place...

They have (the Northern Territory community) had a gutful... They've had a gutful of cars getting smashed up, houses getting broken into, people being assaulted. There's no doubt. And the majority of the community is saying let's lock these kids up (quoted in Dunlevie 2016).

In this characterisation of the reasons underpinning the overrepresentation of Indigenous young people in detention in the Northern Territory we can again see the insistence that Aboriginal kids are the problem, a danger both to themselves and to the broader community. On this analysis their incarceration by the state is seen as the solution to the problem rather than as constituent of the problem itself.

We can see the same problematisations represented in some mainstream media reporting. In early 2018, a number of news reports in the Australian media again addressed the issue of child sex abuse in Indigenous communities, including the shocking report of a two-year-old Indigenous child who was allegedly raped in Tenant Creek, a government report into the national child protection system, and news reporting that mistakenly conflated rates of STI notifications with child sex abuse in remote Aboriginal communities. At the time of these reports, the Assistant Minister for Children and Families, David Gillespie, argued for a change in policy to more easily allow the adoption of Aboriginal and Torres Strait Islander children by non-Indigenous families. Gillespie's statement subsequently informed a segment on the Sunrise morning television program, featuring a wholly non-Indigenous panel with no child protection expertise, discussing the following question: 
A Minister has suggested that white families be allowed to adopt abused aboriginal children to save them from rape, assault and neglect. Does he make a good point?

During the discussion that followed, panellist Prue MacSween, a public relations manager and regular media commentator described removing at-risk children from their homes as a "no brainer' and argued that 'Just like the first Stolen Generation where a lot of children were taken because it was for their well-being, we need to do it again' (quoted in Stuart and Perry 2018).

In a matter of days, this 'debate' had transformed a criminal act of the worst kind - the alleged rape of a two-year-old girl - into a public spectacle that positioned Aboriginal and Torres Strait Islander people as dysfunctional at best, and pathologically criminal at worst. By drawing a straight line from the problem of abused Aboriginal children to white families as the solution, the opportunity for difficult, important and urgent discussion about the current state of affairs in Australia's child protection systems was lost. Further, by framing the issue in such a racialised and simplified manner, Sunrise immediately put Indigenous Australians into a necessarily defensive position: called to fact-check as journalist and $\mathrm{PhD}$ candidate, Amy McQuire did in her response 'Spare us Your False Outrage' (2018) and later seeking three Indigenous Australian practitioners and experts to appear in a 'Special Edition' of the Sunrise 'Hot Topic' segment as a mea culpa for their previous all-white panel. Without irony, the program obscured imaged of protestors outside of their Sydney television studio during the filming of the segment.

The relational dynamic evident in these policy debates and public controversies is well-worn: (1) Aboriginal and Torres Strait Islander people, including children, are represented as a problem to be solved by the settler state; (2) the state then creates and maintains policy interventions into the lives of Aboriginal and Torres Strait Islander people designed to 'solve' that problem (even, as in the case of Closing the Gap, in the absence of any evidence that these 'solutions' are working); (3) public and political debate fails to engage seriously with Aboriginal and Torres Strait Islander peoples' and their critiques of the settler state and its interventions into their lives; (4) Aboriginal and Torres Strait Islander people appear in public debates for the sole purpose of defending and countering racist sensationalism, rather than for opening up new critiques, questions and problems that are worthy of being taken seriously by 
the Australian public. Aboriginal and Torres Strait Islander people are not seen as experts in their own lives and are denied the autonomy they have long sought.

There is much richness in how political science scholars have sought to engage with how Indigenous policy is debated and formulated in contemporary Australia. Of all the subdisciplines within political science, it has been the work of public policy and political theory scholars that has best sought to reveal, challenge and repurpose the dynamics we describe above. There is evidence in the public policy literature of attention to the structural and foundational challenges that the settler state presents for Australian Indigenous policy-making (Maddison 2009; Curchin 2015; Strakosch 2015; Moran 2016; Howard-Wagner 2017; Markham \& Biddle 2018). Alongside efforts by Australian public policy scholars to provide critical contributions that seek to make sense of and problematise dynamics such as those described above, Australian political theorists have sought to critically engage with key concepts that circumscribe Indigenous peoples relations to the modern sovereign state: sovereignty, reconciliation, recognition, forgiveness, conflict, territory and identity have been given various treatments (Muldoon 2003; Muldoon 2005 Muldoon 2008; Muldoon and Schaap 2012; Ivison 2017; Ivison, Patton, Saunders 2001; Little and McMillan 2017; Schaap 2004; Schaap 2008). The purpose of our critique in taking an uncompromising view of what is at stake in Australian politics for Aboriginal and Torres Strait Islander peoples, is to observe that beyond these two subdisciplines, there is a general absence of political science scholarship that seeks to engage directly in understanding (if not destabilising) these dynamics in Australia's Indigenous-settler relations.

\section{The Role of Universities, and Political Science}

In being able to understand the 'problem' of contemporary Australian Indigenous politics and policy as a relational and structural problem, rather than as a problem of people, culture, or of comparative statistical indicators, we argue that the role of universities, and the discipline of political science in particular, ought to be considered differently.

The origins of the university in the Western tradition lie in its firm departure from and challenge to the church's exclusive authority to know and understand humankind. In challenging the church's exclusive authority to know, it follows that the academy and its disciplines have for a 
millenia been preoccupied with establishing and maintaining its own authority. It is an authority grounded not in faith, but in science, in logic and reason, in replicable hypotheses and experiments, in the formulation of more universal languages and codes through which the whole of humanity could know and be known. This pursuit of knowledge is no more the exclusive domain of universities today than it ever was the exclusive domain of the church. We know this thanks to the enduring knowledge systems of Indigenous peoples around the world. That these systems are so difficult for the academy to access, is revelatory both of the limits of the disciplines to know and to the disruptive and damaging impact colonisation has had on Indigenous peoples and the intergenerational and cross-cultural transmission of their knowledge.

Trying to understand what the role of a discipline, such as political science, ought to be in relation to Indigenous peoples is not a straightforward or uncomplicated process. Across the disciplines broadly, Martin Nakata observes that:

In the faculties and disciplines attention to Indigenous issues and content has been a focus of reform and development with varied results over the last two to three decades. Until the late 1960s 'Indigenous' content was taught through the disciplines of archaeology, anthropology and linguistics (Peterson, 1990). Reform in Indigenous affairs, particularly from the time of the Whitlam government (1972) brought forth a burgeoning of research in areas associated with the improvement of the social conditions of Australia's Indigenous people, particularly in education and health. But there was also increased research interest in the ways colonial practice has impacted on us and on revised ways of understanding Indigenous histories, cultures and philosophies. This research now provides much of the content for, and informs, the way we understand Indigenous people and issues within the disciplines (Nakata 2007, 218-9).

There are three domains being described here. First, that of 'colonial' knowledge up to the 1960s, which objectified Indigenous peoples as an ancient and dying race through the scientific gaze in the disciplines of archaeology, anthropology and linguistics. (Disciplines, which, it must be acknowledged, have undertaken deep critical reflection and transformation in their respective engagements with Indigenous peoples in the decades since.) Second, the domain of 
social scientific research which continues today, and which seeks to 'improve' Indigenous peoples but continues to struggle against objectification in the knowledge-making process. The third, and the most recent to emerge, was a critical focus on colonisation itself as transformative of Indigenous peoples, settlers, and the relations between them; foundational to the states and institutions that would develop in colonised territories; and ultimately determinative of what constitutes knowledge itself.

This points to a 'politics of knowledge' that circulates around Indigenous peoples. Canadian political scientist, Karena Shaw, explores this in detail with respect to the critical reflection undertaken within anthropology (Shaw 2003). She writes that this:

delicate political terrain is a highly charged and deeply engaged conversation about authority and disciplinarity, methodology and subjectivity, power and knowledge. What has also emerged is a series of careful attempts to negotiate the terrain, its pitfalls mapped at both the abstract and very immediate levels, as struggles continue about the viability of different anthropological authority in legal and political contexts. Anthropologists are not off the hook, from indigenous [sic] peoples' perspectives, but nor can indigenous peoples [sic] do without them: they are locked together in a complex attempt to decolonise the knowledge practices through which indigenous peoples have been known, have articulated their claims and produced their political subjectivities.

Shaw draws on the practice and politics of anthropology in relation to Indigenous peoples to generate insights with respect to international relations scholarship. Sitting as a subfield within political science, it is a space that has capacity to analyse colonisation as more than historical impact, but also as contemporary power in both a structural and relational sense. However, Shaw is right to be cautious about simply following another discipline's example: "IR has played a different role in relation to those contexts and has its own (although not unrelated) politics of knowledge." (Shaw 2003: 203). Having not undertaken the study of Indigenous peoples as a core part of its disciplinary purpose during the colonial project, it follows that the discipline of politics as a whole has not been called upon to undertake the deep critical reflection and transformation that disciplines such as anthropology have had to work through. The lesson Shaw draws from anthropology for her own scholarly purpose, and which we seek to draw into conversation here in this issue, is to highlight "both the necessity and potential of interrogating the consequences - intentional and unintentional - of knowledge production, as well as the tensions embedded in any effort to do so." (Shaw 2003: 219). The work to be done here is not to re-compose the practice of Australian political science to fix settler relations with Indigenous peoples, but to turn its gaze back upon itself so as to interrogate the consequences 
- intentional and unintentional - of knowledge produced by Australian political science about Aboriginal and Torres Strait Islanders. In Australian political science we must also ask what the consequences of the discipline's relative inattention to Aboriginal and Torres Strait Islanders has been.

There are efforts within the discipline to begin to make sense of itself in relation to Indigenous peoples. In Australia, Will Sanders' review of Indigenous politics in the Australian Journal of Political Science, demonstrating a shift over time from a predominant interest in the 'what' through published sources through to the 'how' and the inclusion of original sources (Sanders 2015: 692). The two dominant subjects of interest across these contributions, he observes, are land rights and mining, followed by social policy. Yet across a nearly fifty-year period, he is unable to identify any full-length article writing by an Indigenous Australian. What is clear across this analysis is that, at least as represented by the journals of the Austral(as)ian Political Studies Association, the engagement of the discipline in Australia with Indigenous experiences and perspectives of political life is minimal. The efforts to engage with Indigenous issues, in whatever context and analytical treatment, have been driven by a handful of scholars against the relative disinterest of the discipline as a whole. In a forthcoming piece, Morgan Brigg and Lyndon Murphy argue that the 'dominant scholarly approach to Indigenous politics is methodologically enables, primarily, by a "structured inattention" which sees Indigenous people not as who they are or might be, but as people adjusting to, and coming to operate through, imported colonial political ideas and systems' (Brigg and Murphy, forthcoming). Having not taken a great deal of scholarly interest in Indigenous people and issues, the political science discipline's 'structured inattenion' is one that requires a different intellectual response from those disciplines characterised by structured attention.

Karena Shaw's work highlighted above demonstrates how and why the centering of Indigenous peoples to the study of political science (and more specifically, the subdisciplines of political theory and international relations) is so essential. While it cannot engage with the concept of 'structured inattention', her 2008 book, Indigeneity and Political Theory, offers an intellectual framework that responds well to the problem of structured inattention. Her book is framed around one simple question: "what might it mean to "rethink the political" under contemporary circumstances?' (Shaw 2008: 2). The contemporary circumstances she refers to those that account for ongoing practices of colonisation, the transformative impacts of globalisation on the world order, and changing ecological systems. In asking this question, Shaw does not turn 
to Indigenous people as a focal point for study, and in this sense she maintains the discipline's inattention. However, in making colonisation a key condition of the contemporary world, her question demands an engagement with Indigenous peoples as a way of making sense of politics: there is no contemporary international order composed of sovereign states without the dispossession of Indigenous peoples from land. For Shaw, contemporary politics is framed by discourses of sovereignty. These discourses of sovereignty provide the foundation of modern politics, and that foundation is premised upon the constitutive presence of Indigenous peoples through their dispossession. She puts it this way:

...even as Indigenous politics are framed by these discourses and practices, they also, in part because of their centrality to them, expose, denaturalize, and reformulate them.

The challenges posed to discourses of sovereignty by Indigenous politics are thus important not only because unless these discourses are challenged and the realm of the political reformulated, Indigenous politics will continue to be forced between impossible alternatives, but also because the problems confronted by Indigenous peoples in relation to sovereignty discourses are not only "their" problems, but go the heart of contemporary understandings and practices of politics (Shaw 2008: 9).

Political science has thus far evaded any comprehensive engagement with the challenges posed by Indigenous peoples in large part by centering the study of settler politics and political institutions while marginalising Indigenous peoples and politics as an empirical object of study understood primarily as a social movement or a policy problem, rather than as part of the foundation of contemporary politics itself. Whereas feminist political science has advanced as a discipline-wide critique of the impact of male-dominated and masculine political institutions on the lives of women, there has not been a concomitant Indigenous political science that has subject settler institutions to the same critique. The feminist contribution to political science has not just been to give attention to women, or to add them into existing political institutions and practices, but to reveal the gendered character of politics itself. Politics is what it is, because of women's relations to it. We are gently trying to find our way toward a way of thinking about politics as something that is what it is because of Indigenous relations to it. 
With a few notable exceptions, mainstream political scientists have not considered an Indigenous politics as central to the study of political parties, electoral systems, federalism, political economy, or parliamentary politics. These absences rest on a number of problematic assumptions: Indigenous peoples are understood as unimportant minorities within liberal multicultural polities; Indigenous peoples' experiences are positioned as marginal to the functioning of mainstream politics; mainstream politics itself is understood in neutral liberal terms rather than as colonial and as still colonising; Indigenous political participation is seen as desirable but not essential, and only on settler terms; Indigenous political systems are rendered invisible and/or insignificant; the authority of settler political institutions in Indigenous lives is seen as appropriate and unproblematic rather than as a colonising practice that fails to acknowledge Indigenous sovereignties. Each of these assumptions leaves the practice of politics impoverished, while simultaneously doing harm to Indigenous peoples.

At the same time, the discipline of political science has largely not found itself moved to intervene and disrupt these assumptions. While Indigenous affairs policy is analysed and critiqued, the right of the settler state to make such policy is rarely questioned. While it is seen as desirable to elect more Aboriginal and Torres Strait Islander people to settler parliament, the right of these parliaments to govern Indigenous lives is similarly unquestioned. Both the politics, and the study of politics, in Australia has paid grossly inadequate attention to Indigenous politics in ways that continue to cause trauma in Aboriginal and Torres Strait Islander lives. It is beyond time for the discipline to decentre its presumed right to know Indigenous peoples and politics in favour of a new agenda focused on the centering of the relationship between Aboriginal and Torres Strait Islander peoples and the state as foundational to the nation and fundamental to its contemporary politics.

The concerted efforts of those who are engaging the discipline with Indigenous issues do so in ways that we argue are helpful and instructive for thinking about why we ought to, and how we might be able to, meaningfully and productively centre Indigenous peoples and their politics within the study of political science. To pursue anything less is to serve the continued violence of the settler state against Indigenous peoples in Australian and around the world, and to do a profound intellectual disservice to the discipline.

\section{A new research agenda}


Through our work as co-directors of the Indigenous Settler Relations Collaboration at the University of Melbourne, we seek (among other aims) to expand the disciplinary attention of political science to Indigenous peoples and politics in two modes:

First, by seeking to develop questions that can be posed to the discipline, rather than from the discipline, to deepen our understanding of how and why the discipline operates in relation to Indigenous peoples and politics in the ways that it does. Here, our interest in Indigenous-Settler relations incorporates the discipline of political science as part of the settler order that both governs and can work to reframe those relations.

Second, to develop an ethical starting point for developing questions asked from the discipline to Indigenous peoples and politics. We think this ethical starting point can be informed, today, by two things: (1) by engaging with the varied and diverse political claims of Indigenous peoples, and their problematisations of contemporary politics; (2) by making the relations between Indigenous peoples, settlers, and the settler state the focal point of inquiry rather than the lives and bodies of Indigenous peoples. In these two moves, we seek to centre the political expressions of Indigenous peoples and the relations between these peoples and the settler order, while de-centering the authority of the discipline to know Indigenous peoples. Framed by these ethical positions and the de/centering moves we are seeking to advance, the ISRC looks to explore what might inform, shape and give life to more just relations between Indigenous and non-Indigenous peoples.

In concluding, we wish to make it that this research agenda does not seek to reduce Indigenous peoples and their politics in Australia and around the world to their relations with the settler order. Indigenous peoples exist in meaningful, substantive, embodied, powerful ways that are independent from the violence of colonisation that has bound them to the state. To the extent that Aboriginal and Torres Strait Islander peoples sustain lives and political practices separate and apart from the settler-colonial state, it is only task of political science scholars to study those political practices when asked by Indigenous peoples themselves. Too much harm has already been done by scholars from a range of disciplines who have sought to make Indigenous peoples knowable to the settler mainstream. That is not our task here. Australian political science that does not account for its relationship to Aboriginal and Torres Strait Islanders in the way that it addresses institutions, policies, agents, structures and so forth is a political 
science that cannot fully understand its power or the knowledge it produces. The purpose of political science, is to understand, critique, and challenge the structures, agents and relations of power that govern our world(s). Structures and agents in Indigenous politics have received some attention, but it is the relational dimension that requires expansion. Until our discipline can make sense of itself in relation to the ways in which it has pursued knowledge of Indigenous peoples and politics, and until it can accept the decentreing its own authority to know these relations, political science will not have the epistemological capacity to know all that lies beyond those relations.

\section{Bibliography}

Bock, Andrew. 2014. 'Rise of Aboriginal PhDs heralds a change in culture', Sydney Morning Herald, 17 March, <https://www.smh.com.au/education/rise-of-aboriginal-phds-heralds-achange-in-culture-20140316-34vqm.html>

Brennan, Bridget. 2017. 'Australia's progress on Closing the Gap "woefully inadequate”, UN says', ABC News, 11 September, <http://www.abc.net.au/news/2017-09-11/closing-the-gapprogress-woeful-un-says/8892980>

Curchin, Katherine. 2015. 'Two visions of Indigenous economic development and cultural survival: The "real economy" and the "hybrid economy", Australian Journal of Political Science, vol. 50, no. 3, pp. 412-426.

Carson, Bronwyn; Dunbar, Terry; Chenhall, Richard; and Bailie, Ross, 2007, Social determinants of Indigenous health, Allen and Unwin, Sydney

Davidson, Helen. 2018, 'Closing the Gap "refresh": Coalition accused of ignoring Indigenous Australians', The Guardian, 2 January, <https://www.theguardian.com/australianews/2018/jan/02/coalition-accused-of-ignoring-indigenous-australians-in-closing-the-gaprefresh> 
Davis, Megan. 2016. 'Scant recognition: Have Aboriginal and Torres Strait Islander Peoples any reason to hope? ABC Religion and Ethics, 11 August, http://www.abc.net.au/religion/articles/2016/08/10/4515798.htm

Davis, Megan. 2018. 'Correspondence - The status quo ain't working: why the Uluru Statement from the Heart is a blueprint for Australian democracy' Quarterly Essay vol. 70, pp. 128-130.

Department of Prime Minister and Cabinet. 2017. 2017b, Closing the Gap Prime Minister's Report 2017, Commonwealth of Australia, <https://closingthegap.pmc.gov.au/sites/default/files/ctg-report-2017.pdf>

Dunlevie, James. 2016. 'John Elferink sacked from Corrections in wake of Four Corners report; Adam Giles alleges culture of cover-up', $A B C$ News Online 26 July, accessed at: <http://www.abc.net.au/news/2016-07-26/nt-prisons-minister-john-elferink-sacked-after-4corners-outrage/7661086>

Grant, Stan. 2016. Talking to my country, Melbourne: Scribe Publications

Gunstone, Andrew. 2009. Unfinished business: The Australian formal reconciliation process, 2nd edn, Melbourne: Australian Scholarly Publishing

Howard-Wagner, Deirdre. 2017. 'Governance of indigenous policy in the neo-liberal age: indigenous disadvantage and the intersecting of paternalism and neo-liberalism as a racial project', Ethnic and Racial Studies, https://doi.org/10.1080/01419870.2017.1287415, pp. 1-20.

Ivison, D. 2017. Pluralising political legitimacy. Postcolonial Studies, 20(1), 118-130.

Ivison, D., Patton, P., Sanders, W. 2001. Political Theory and the Rights of Indigenous Peoples. Cambridge: Cambridge University Press.

Ivison, D. (2002). Postcolonial Liberalism. Cambridge: Cambridge University Press.

Klein, Elise. 2016. 'Look up: How policy gaps and failure blind us to what's going on in Indigenous affairs', The Conversation, 2 December, <https://theconversation.com/look-uphow-policy-gaps-and-failure-blind-us-to-whats-going-on-in-indigenous-affairs-69465>

Little, A., McMillan, M. (2017) 'Invisibility and the politics of reconciliation in Australia: keeping conflict in view' Ethnopolitics, Vol. 16 (5), pp. 519-537. 
Maddison, Sarah. 2009. Black politics: inside the complexity of Aboriginal political culture. Sydney: Allen \& Unwin.

Markham, Francis \& Biddle, Nicholas. 2017. 'Radical rethink of Closing the Gap required, despite some progress', The Conversation, 4 December, <https://theconversation.com/radicalrethink-of-closing-the-gap-required-despite-some-progress-86203>

McQuire, Amy. 2018. 'Spare us your false outrage', IndigenousX, 13 March, <https://indigenousx.com.au/amy-mcquire-spare-us-your-false-outrage/\#.W0mmjNgzbq0>

Moran, Mark. 2016. Serious Whitefella stuff: When solutions became the problem in Indigenous affairs, Melbourne: Melbourne University Press

Muldoon, Paul. 2003. 'Reconciliation and political legitimacy: the old Australia and new South Africa', Australian Journal of Politics \& History, Vol 49(2), pp. 182-196.

Muldoon, Paul. 2005. 'Thinking responsibility differently: reconciliation and the tragedy of colonisation', Journal of Intercultural Studies, Vol. 26(3), pp. 237-254.

Muldoon, Paul. 2008. 'The sovereign exceptions: colonization and the foundation of society', Socio \& Legal Studies, Vol 17(1), pp. 59-74.

Nakata, Martin. 2007. Disciplining the savages: Savaging the disciplines, Canberra: Aboriginal Studies Press.

Patterson, Michelle, 2017, Commonwealth Machinery of Government in Aboriginal and Torres Strait Islander Affairs: 50 years of Commonwealth Public Administration in Aboriginal and Torres Strait Islander Affairs, IAG Working Paper Series. No. 1, Aboriginal and Torres Strait Islander Affairs Group, Canberra: Department of the Prime Minister \& Cabinet

Pratt, Angela, 2005, Practising reconciliation? The politics of reconciliation in the Australian Parliament, 1991-2000, Canberra: Parliament of Australia Parliamentary Library

Referendum Council. 2017. Uluru Statement from the heart, 26 May, 
<https://www.referendumcouncil.org.au/sites/default/files/2017-

05/Uluru_Statement_From_The_Heart_0.PDF>

Sanders, Will. 2015. 'Indigenous politics in the Australian Journal of Political Science: A review', Australian Journal of Political Science, vol. 50, no. 4, pp. 679-694.

Schaap, Andrew. 2004. 'Political reconciliation through a struggle for recognition?', Social and Legal Studies, Vol. 13(4), pp. 523-540.

Schaap, Andrew. 2008. 'Reconciliation as ideology and politics', Constellations, Vol. 15(2), pp. 249-264.

Shaw, Karena. 2003. “Whose Knowledge for What Politics?”, Review of International Studies, Vol 29, pp. 199-221.

Shaw, Karena. 2008. Indigeneity and Political Theory: Sovereignty and the Limits of the Political, London: Routledge Press

Short, Damien. 2005. 'Reconciliation and the problem of internal colonisation', Journal of Intercultural Studies, vol. 26, no. 3, pp. 267-282

Strakosch, Elizabeth. 2015. Neoliberal Indigenous policy: Settler colonialism and the 'postwelfare' state, Basingstoke: Palgrave Macmillan

Stuart, Riley and Perry, Jodan. 2018. 'Sunrise debate about Indigenous children sparks large protest in Sydney's Martin Place', ABC News, 17 March, <http://www.abc.net.au/news/201803-16/sunrise-protest-held-in-martin-place/9554832>

Walter, Maggie. 2018. 'The voice of Indigenous data: beyond the markers of disadvantage', Griffith Review: First Things First, Vol. 60, pp. 256-270.

Wolfe, Patrick. 2016. Traces of history: Elementary structures of race, London: Verso 



\section{University Library}

\section{- M M N E R VA A gateway to Melbourne's research publications}

Minerva Access is the Institutional Repository of The University of Melbourne

Author/s:

Nakata, S;Maddison, S

Title:

New collaborations in old institutional spaces: setting a new research agenda to transform Indigenous-settler relations

Date:

2019-07-03

Citation:

Nakata, S. \& Maddison, S. (2019). New collaborations in old institutional spaces: setting a new research agenda to transform Indigenous-settler relations. AUSTRALIAN JOURNAL OF POLITICAL SCIENCE, 54 (3), pp.407-422. https://doi.org/10.1080/10361146.2019.1626347.

Persistent Link:

http://hdl.handle.net/11343/292090 